\title{
Building Different Corporative Videoconference Scenarios on VCON HD3000 System Example
}

\author{
Marjan Milošević and Radojka Krneta \\ Technical Faculty Čačak, \\ University of Kragujevac, Serbia
}

\author{
marjan@tfc.kg.ac.rs, \\ radojka@tfc.kg.ac.rs
}

\author{
Vladimir Zoćević \\ Agromehanika Čačak, \\ Serbia
}

obilics@yahoo.com

\begin{abstract}
The focus of this article is directed towards the practical usage of videoconference systems in different corporative scenarios, where the special attention is given to the VCON HD3000 system and its usage in corporative learning and arrangement of virtual meetings. Since the education of the human resources is necessary for the development and advancement of every company, the prime goal of the management is to find the ways for accomplishing the process of education on the highest level possible, together with the reduction of the following expenses. The purpose of this work is to show that it is exactly the use of video conferencing that could enable both of these, apparently exclusive goals. Visual collaboration products such as videoconferencing can increase the quality of users' business communication experience. By improving this experience, the frequency of use and productivity can grow.
\end{abstract}

Keywords: videoconference, VCON systems, corporative learning, virtual meetings

\section{Introduction}

The huge growth of the available information quantity, as one of the major characteristics of modern business, has increased the learning requirements, which in the recent time has been pronounced more than ever. Daily inflow of new information and continuous obsolescence of present ones accompanied by constant changes in business environment irretrievably results in the necessity of education of employees which enables companies to keep pace with changed circumstances (Boord, 1997, p. 152). Within a business context, learning is a process through which the existing knowledge and skills are broadened and new ones are acquired, which provides easier attaining of new set objectives. Learning, within a business context, is also commonly known as corporative learning.

Corporate learning is not a new phenomenon. Employees have always been indulged in learning

Material published as part of this publication, either on-line or in print, is copyrighted by the Informing Science Institute. Permission to make digital or paper copy of part or all of these works for personal or classroom use is granted without fee provided that the copies are not made or distributed for profit or commercial advantage AND that copies 1) bear this notice in full and 2) give the full citation on the first page. It is permissible to abstract these works so long as credit is given. To copy in all other cases or to republish or to post on a server or to redistribute to lists requires specific permission and payment of a fee. Contact Publisher@InformingScience.org to request redistribution permission.
(Spencer, 2006).

Moreover, large companies, such as IBM or Motorola, founded in-house mini-universities, providing the employees with more or less formal kinds of education, including certificated programs, using traditional tools and elearning (Tai, 2008).

In the time of economic crises and turbulent markets a company's investing in 
staff education and slashing the company administration costs are seemingly two opposite objectives. The introduction of online training-and videoconferencing (VC) into business practice provides unification of these two objectives. Training is a clear case where videoconferencing can save companies money, and their employees' times and energy (Turek, 2009).

A videoconference connects two or more sites with audio and video links so that participants can converse, interact, and share documents. As a distance education tool, videoconferences help teachers reach any students who are isolated in distance or time from an instructor (Northwest Regional Educational Laboratory, 2000). In business context, VC can be used for different purposes, like:

- Staff development and training

- Departmental meetings

- Staff organizational meetings

- Individualized Educational Plan (IEP) development and advice

- Job candidate interviews

Modern technology enables employees to learn when they please and to the extent they need. Visual collaboration products such as videoconferencing can increase the quality of users' business communication experience (Frost \& Sullivan, 2009).

In terms of quality and costs, online courses and videoconferences are the most applied means of education. Numerous advantages arising from these forms of education make videoconferences and distance learning courses more attractive, thus suppressing traditional learning methods (Prusak 1997, p. 89).

The analysis of corporate learners' requirements shows up several aspects:

The rapid advancement of technology; the need for life-long learning; and increasing experimentation with distance learning. Together these trends are causing a severe change and putting enormous pressure on the traditional educational system to forever alter the way it does business. A new landscape of higher education is emerging one, where the private sector will eclipse the public sector as the educator of choice for the non-traditional working adult student. (Meister, 1998)

An efficient way to acquire knowledge, as befits the adult learner, can be described as follows:

1. Any new knowledge builds on previous knowledge

2. Emphasizing comprehension is a meaningful way of building on our fund of knowledge

3. Trying to comprehend and evaluate theoretical information through practice

4. Learning is based on the learner's own activity

5. Social interaction has a central role in learning

6. Flexibility in training arrangements supports the adult learner's level of autonomy

Principles 3, 4 and 5 may be properly fulfilled using the videoconferencing.

\section{Videoconference Corporative Scenarios}

Some of the most common situations where VC systems are used are corporative learning and arrangement of virtual meetings. Arranging of these scenarios will be shown on actual VC system VCON HD3000 because it is the system that the authors have a lot of practical experience with. For both of these scenarios there will be given a short description for using VCON HD3000 system. 


\section{VCON HD3000 System}

The HD3000 is a set-top conferencing system combining videoconferencing, streaming video, and multipoint conferencing. The HD3000 provides several distinctive attributes and features which makes it an ideal solution for many group videoconferencing environments. The HD3000 system consists of a main unit (it contains the video card, software for system operation, a built-in Pan/Tilt/Zoom (PTZ) camera, and various connectors located on the rear panel for connecting other components and accessories, such as VCR) and remote control set. Beside the numerous options that make system easy to use, there is the option for free moving camera, and option to set up to six pre-set positions for instant recall of camera.

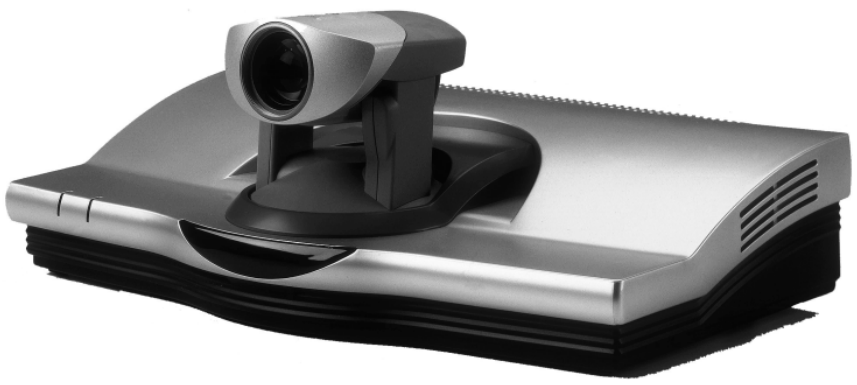

Figure 1: The main unit of $\mathrm{HD3000}$ system

The system is capable of sending audio and video signals, both with data (i.e. from the PC), so the remote party may present both the teacher and presentation (Milosevic, 2008). This feature is called simulcast.

Additional equipment that can be bought later if user needs, contains of TV monitor, document camera, additional cameras and speakers.

In Table 1 a brief comparison of three set-top videoconferencing systems (VCON, Sony, Polycom) is given (Polycom, 2004; Sony, 2008; VCON, 2004).

\begin{tabular}{|l|l|l|l|}
\hline \multicolumn{3}{|c|}{ Table 1: Comparative preview of three set-top VC systems } \\
\hline & vCON HD 3000 & Sony PCS-XG80 & Polycom-VSX 8400 \\
\hline Inputs & S-video, composite & S-video, composite, RGB & 2 S-video, DB15, RGB \\
\hline Outputs & S-video, 2 composite & HDMI, RGB & 3 S-Video, RGB \\
\hline Resolution & CIF, QCIF & CIF, 4CIF, 720p, 1080i & XGA, SVGA, VGA \\
\hline MCU & 4 participants & 6 participants & 4 participants \\
\hline Standards & H.261,H.263, H.264 & H.261,H.263, H.264 & H.261,H.263, H.264 \\
\hline $\begin{array}{l}\text { Integra- } \\
\text { tion with }\end{array}$ & $\begin{array}{l}\text { MXM management serv- } \\
\text { er }\end{array}$ & - & Cisco Call Manager \\
\hline Other & Dual stream & H.239 (dual stream) & Intelligent QoS \\
\hline
\end{tabular}




\section{VC Presentation Rooms and VC Session Preparation}

In order to describe how, potentially, this videoconference system can be used for corporative learning and virtual meetings in the following text there will be given an explanations about using this system. The following text will not contain any information about installing system, because there is an assumption that HD3000 system has been already installed in specific institution. The presentation room is the center of production for a videoconference class (or virtual meetings, etc.). Having the room and the presentation area organized goes a long way toward smooth and effective delivery. Some of the useful tips that follow address many details of arranging materials and setting up the room to minimize distractions during a videoconference presentation:

- Write out step-by-step instructions for connecting, using equipment, and contacting offsite troubleshooters, and keep them nearby.

- Mark off with masking tape and clearly label areas used for sitting and working; do the same for spaces used for cameras, overhead projectors, and other equipment.

- Use a large desk or table with a panel covering in the front.

- Work closely with an assistant, if possible, to help with cameras and other equipment; have the assistant remain in the room during the entire class.

- Set the presentation camera at eye level with the viewing monitor so that the presenter can easily and naturally look into the camera broadcasting to receiving sites.

- Check for effective lighting:

- Use additional lights to illuminate the presentation area if the room is dark or shadowy.

- Set up and readjust lights before each class.

- Keep camera remote controls close for easier switching between cameras.

- Place the document camera on the presentation desk.

- Design a backdrop for the presentation room that establishes an appropriate tone for the class:

- A bulletin board with student work (photos, drawings, graphic designs, etc.) can be changed periodically.

- Rolling bulletin boards are also an option, though expensive.

Additionally, the special attention should be paid upon preparation and structuring of audio and video systems to provide appropriate quality of communication and interaction per each conference participant.

\section{The Use of VCON HD3000 System in Corporative Learning}

This scenario provides a conference in which the instructor presents his lecture on the topic, where learners have the opportunity to pose their questions in predefined parts of class. The instructor should know where the lecture is intended, or who are participants in order to accommodate subject to their needs and have designed their teaching so that students leave enough time asking questions to resolve ambiguities and uncertainties. The terms teacher and instructor are used interchangeably. However, this role is usually devoted to individuals working at the organizations training department, senior colleagues and so on, regarding the actual situation in the business environment. 
The following two scenarios are the most common when we talk about teaching from/to remote location:

1. teacher holds a lecture to an individual (individuals) at a remote location (locations) (Figure 2)

2. teacher keeps teaching multiple learners at a remote location (locations) (Figure 3)

Of course, in both cases above, it often happens that, at the same time, the teacher educate both „remote" students and students who are physically present in the area of instruction. Related to this, we can say that videoconferencing has succeeded, if the quality of teaching was at the same quality level both for local and for remote students. This presumes the appropriate quality of video and audio, without lags and adequate opportunity of interaction for the remote students.

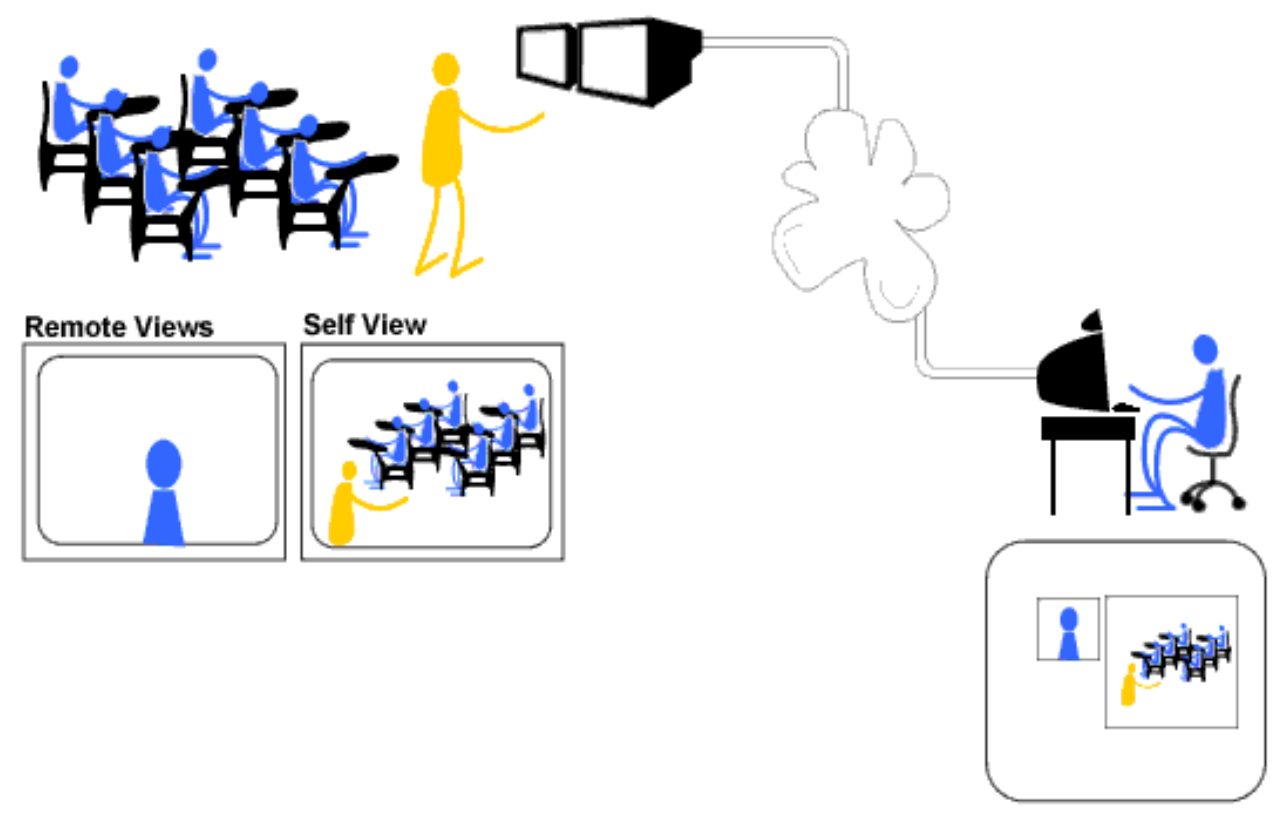

Figure 2: A teacher holding a lecture to an individual (individuals) to one or more remote locations (The Global Development Learning Network, 2005)

In figure 2 there is showed such scenario where instructor can toggle between lecture mode and discussion mode during the session. Camera B is active for the lecturing. Switching to camera A instructor gives the participant better view for the discussion.

It is important to note that VCON's HD3000 system, thanking to the MCU device allows the simultaneous participation of four participants in the videoconference at a speed of $384 \mathrm{Kbps}$, or three participants with a top speed of $768 \mathrm{kbps}$. In practice, this means that the teacher can also hold a lecture that can be monitored in four remote areas that may be thousands of miles away from the place where he is. If the number of remote locations is greater than one, it is a multipoint conference, and if a lecture is intended for one remote location, it is a point-to-point conference. HD 3000 is fully compatible with ITU-T recommendations H.320/H.323. It means compatibility VCON systems with communications, networking and terminal equipment of other manufacturers and make possible to create reliable inexpensive multimedia networks, optimized for any practical applications.

The basic system may be extended both with hardware and software components (VCON, 2010a). Using the MXM management platform, it is possible to control many endpoints remotely, setting various parameters, such as time scheduling, resource allocation etc. 
Home users may also participate in the video conference using their PC, equipped with speakers and microphone and appropriate software - vPoint HD (VCON, 2010b).

The communication encryption is supported and desired in most situations, especially in scenarios including sensitive data, such as business meetings.

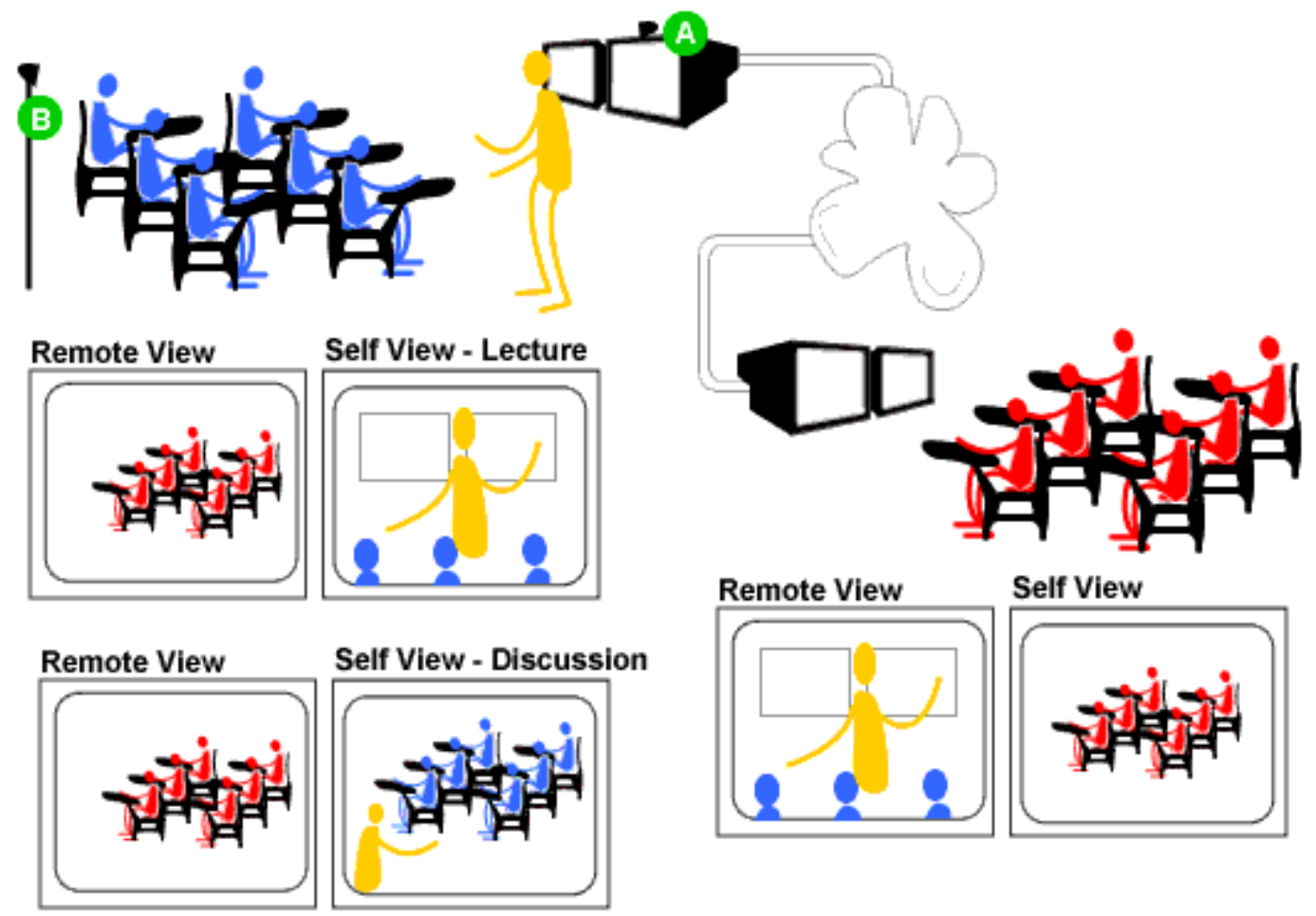

Figure 3: A teacher holding a lecture to large number of students at a remote location (s) (The Global Development Learning Network, 2005)

The following is a brief guide to the preparation and use of videoconferencing in which the teacher holds a remote lecture to a remote location (point-to-point conference). An example of multipoint lecture is almost identical to the maintenance of multi-point virtual meetings, so it will be described later, in the virtual meeting's scenario.

It is necessary to make a strong effort to get the equipment well prepared before the conference begins. The practice emerged a recommendation to use both web-interface and remote control in favor of getting the most efficient system operation. It is suggested to store needed data (IP addresses, speed etc.) previous to the call. Additionally, it is well practice to also memorize several key camera positions, so no adjustment should be done after the session begins. The HD 3000 is equipped with a table microphone, which is capable of getting sound from all over the moderately big room. Alternatively, separate microphones may be used. In case of multipoint conference, having a single microphone is not recommended.

It is strongly recommended to double check the network availability, having the planned speed of connection reduced if necessary.

In general, needs for any administrative activity during the very session should be minimized, avoiding the idleness and having the participants focus on the session subject. 
The HD3000 system offers the possibility of connecting two monitors to monitor full-screen image both from the place where the teacher holds lectures and from the remote location. If there are not two monitors, it is possible to select images on the current screen so that it shall display either from the place of lectures, or from a remote location (selection is done by pressing the Display button on the remote control).

\section{Remote Teaching with VCON HD3000}

After settings have been made, the teacher can start with teaching. In addition to the classical theoretical lectures, the system offers some additional tools to the teacher, such as the use of a maximum of two additional cameras, video recorder, DVD drive, share documents and applications, video streaming etc.

HD 3000 is capable of streaming using the multicasting. If the multicasting across the Internet is not supported, then it is still possible to make a multicast streaming in the LAN. This may be of interest playing the stream in separate room connected to the same LAN segment.

Sharing data and applications is also very useful, since it allows the teacher and students physically present on the one hand, and those who follow the lecture in a remote location, on the other hand, to exchange files, view a specific project at a time, or analyze the specific applications of that study.

If the other party has installed HD system, then it is possible to transfer two streaming at the same time (video data). If the other party has a monitor, shared applications are displayed full-screen, and images from the lectures of the picture-in-picture window in a corner of the screen. If the remote party has two monitors, one shows a shared application, and the other shows place of instruction. This feature is called simulcast.

Sharing can be done if the other party that participates in the conference does not have HD system installed. In this case, remote locations receive a shared application, not the image of the broadcast. Running application sharing is the same in the same way as streaming media, but it is necessary to install and run HD Data Utility program at both locations.

Combination of lectures and activities - that is the best method for transferring knowledge. Listening to lectures and then applying it through simulation exercises and the like enable employees to adopt knowledge in a way that ensures its long-term retention and practical application in the workplace.

\section{Maintaining a Virtual Meeting via VCON HD3000 System}

Meetings via videoconferencing are one of the most common present usage scenarios for these technologies. Instead of the former traditional meetings that have involved high transport costs and several hours of absence from work which resulted in the reduction of productivity, it is now possible to arrange a meeting within a few moments, with one click to a button without leaving the workplace. Maintaining the benefits of traditional "face-to-face" meetings, while reducing maintenance costs and loss of time, minimizing the reduction in productivity and efficiency, videoconferencing have found wide application in the organization of meetings in one or more companies.

The increasingly virtual workplace offers any number of benefits, but one thing gets lost in the translation: Team building. It is tough for employees to develop deep and lasting relationships when they rarely see each other and communicate mainly via phone, e-mail and chat. But videoconferencing can change that, by making it possible for team members to see each other on a daily or weekly basis. Simply making that visual connection makes contact more personal—and 
that makes it easier for people to work together, because they feel like they actually know the people they are working with (Turek, 2009).

When we are talking about using VC system in the organization of virtual meetings, we can say that there are two main subscenarios, which can still be divided:

1. point-to-point subscenario - refers to meetings between the two remote locations (point-topoint conference), and there are usually three situations of interest:

a. One to one (a meeting attended by two physically remote people, here it is possible to use a desktop videoconferencing)

b. One to many (the meeting is held between two remote locations - at one place there is an individual who may use the desktop videoconference, on the other there are more than one person, who use room videoconferencing)

c. Many to many (group of people on each remote locations)

2. multi-point subscenario - the holding of meetings between more locations (VCON HD3000 provides up to four locations) that are separated from each other (multi-point conference), and as in the previous case, here are a few cases that occur:

a. One to one (a meeting attended by individuals who are located in several locations (three, four locations))

b. One to many (this subscenario is usually present in situations where one of the leaders of company chairs the meeting attended by groups of remote employees, often situated in remote offices of the company)

c. Many to many (on any site that is included in the meeting there is a greater number of people)

d. Possible combination of the previous cases

Figures 4, 5, 6 and 7 show some of the possible scenarios and subscenario of using VC systems for virtual meetings (The Global Development Learning Network, 2005). 


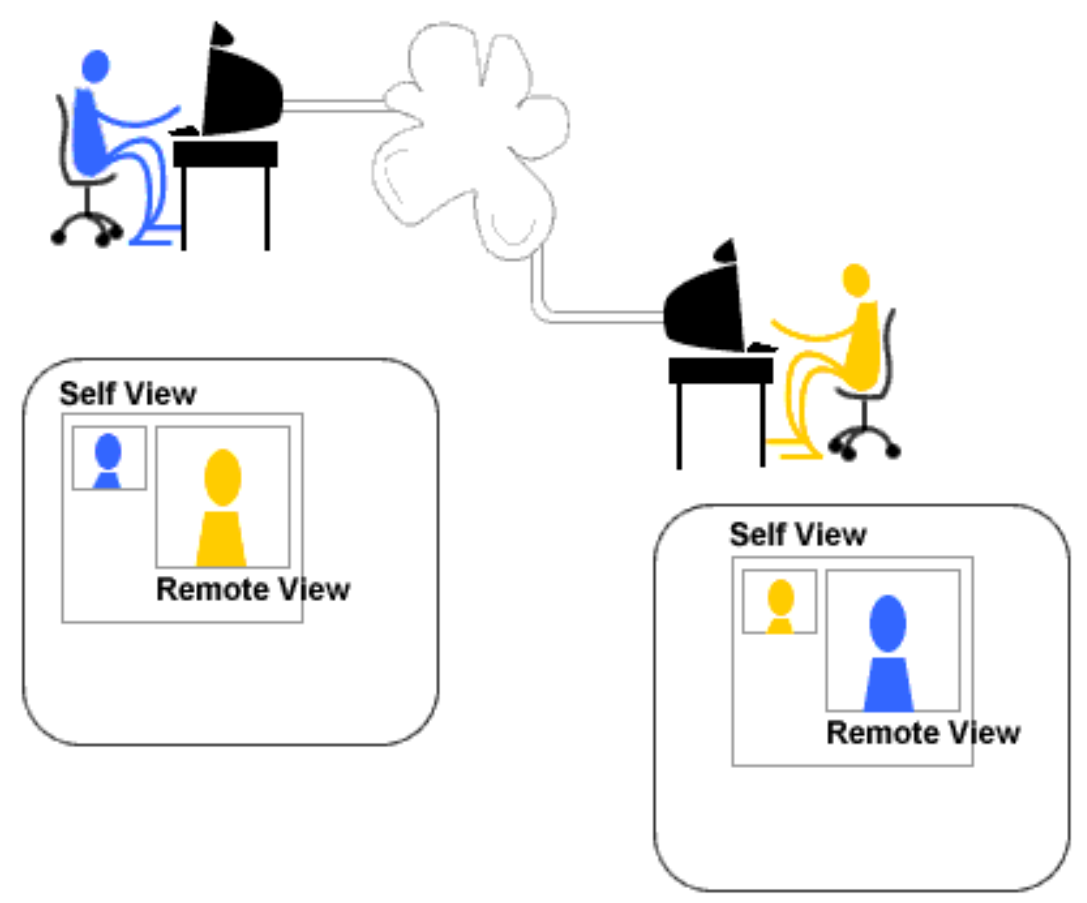

Figure 4: Point-to-point subscenario (meeting - one to one)

(The Global Development Learning Network, 2005)

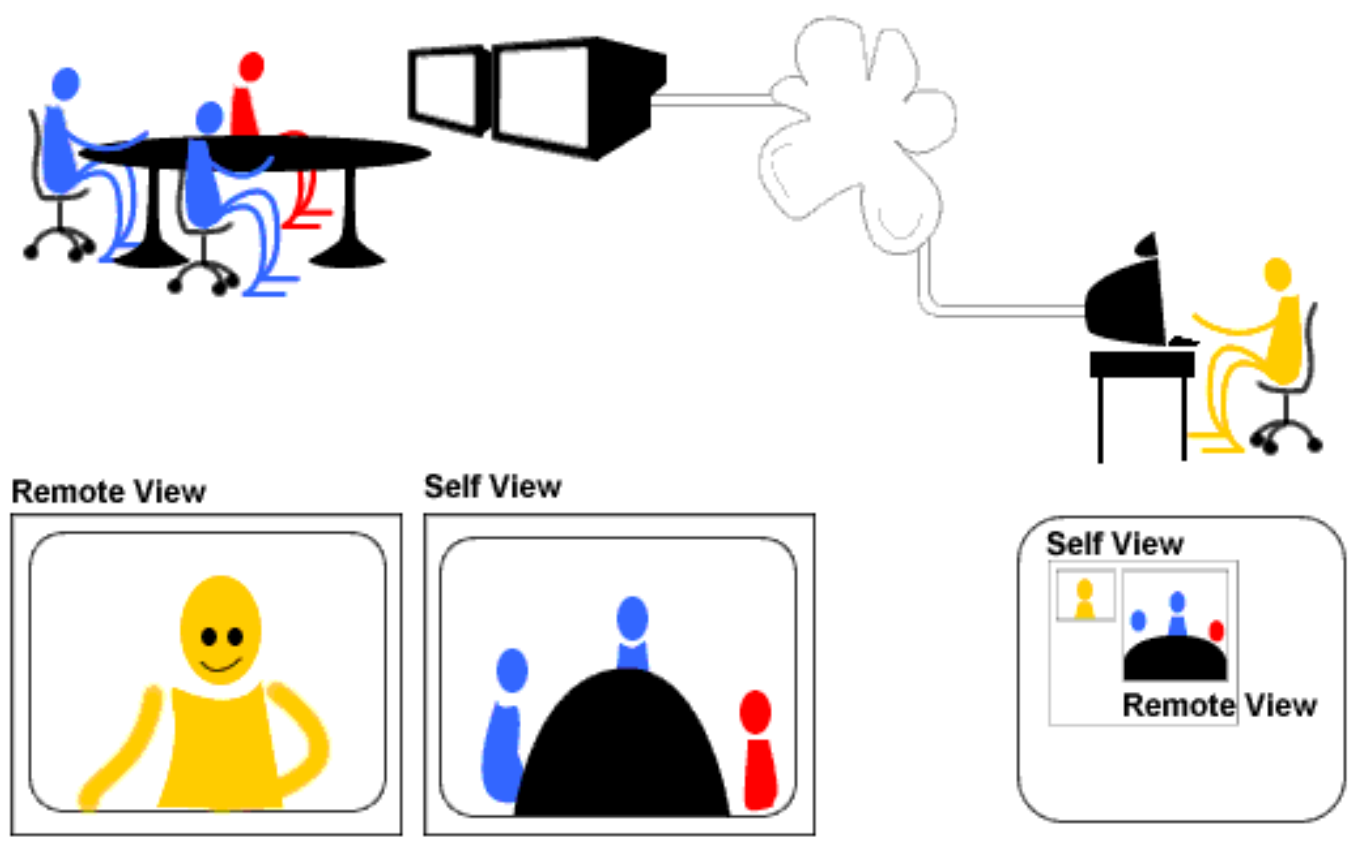

Figure 5: Point-to-point subscenario (meeting - one to many)

(The Global Development Learning Network, 2005) 
Most systems allow the Point-toPoint conference with only one monitor. In such case, the self view comes up inside a "picture-in-picture" window on the main monitor (Figure 6).

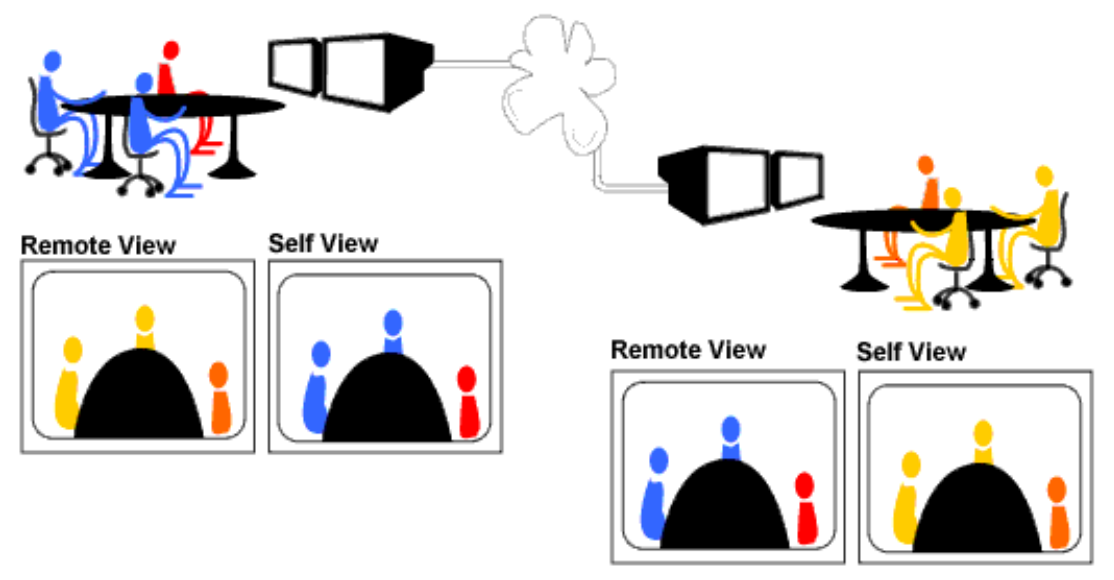

Figure 6: Point-to-point subscenario (meeting - many to many) (The Global Development Learning Network, 2005)



Figure 7: Multi-point subscenario (meeting - one to many)

(The Global Development Learning Network, 2005)

MCU's vary in their capabilities and in their screen layouts. Some higher end conference room codecs include MCU capabilities for up to four sites (Figure 7). Such example is HD3000.

Since the organization of meetings on the principle of point-to-point videoconference is the same as lectures on the same principle, the following chapter will deal with the scenario of the meeting attended by a number of people in multiple locations (multi-point videoconferencing, many to many - Figure 8). 




Figure 8: Multi-point meeting (many to many)

\section{Maintaining Multi-Point Virtual Meeting via VCON HD3000 System}

HD3000 system allows user to create a cascade of multi-point meeting, which in practice means the following - A user with her/his HD3000 includes users of K1, K2 and K3 in the multi-point conference. User K3 also has a system HD3000, and it invites new users K3.1 and K3.2, so they associated with the user A. In this way 6 participants participate in meeting (A, K1, K2, K3, K3.1 and K3.2). Images from a user's location are shown as the main video on the monitors of all other participants. The only exception is User A, because his/her local position is displayed as ,picturein-picture"

When we talk about the classical multi-point meeting via VCON HD3000 system, it is necessary to make certain settings, according to which these meetings can be divided into several groups:

1. according to what the participants see:

a. the monitors of all participants display a picture from the site where the participant is currently speaking

b. the monitor displays the images of all other participants in the meeting

2. according to what the participants hear:

a. users from all sites only hear the voice of one who currently holds the speech

b. users hear each other at any time during the conference

3. according to who controls the process of the meeting:

a. no control - users hear and see each other all the time, so here it is desirable to choose by consensus the Chairman of the meeting, which will give and deprive the word to avoid general chaos

b. control in the hands of the presidency - he has mechanisms that exclude and include others in the meeting 
c. control in the hands of one location - similar to the previous case, one location is determined when and how long the other sites are included, and when and how others can hear and see.

After settings and the way of meeting had been made, it can begin. In addition to traditional presentation and constructive discussion, the HD3000 system enables media streaming and sharing of data and applications in multi-point videoconferencing.

Multicast can be applied to all types of meetings, whether it is an open meeting, during which all participants see and hear each other, or in terms of meetings chaired, by the appointee. If the control is in the hands of the Chairman of the meeting, then each party must send a request to that person if they wish to determine the stream material. Searching for permission looks like this - on the remote control push button Multipoint, after which should be confirmed with OK. Upon completion of streaming, the license should be returned in the same manner as is required (Multipoint, and confirmation that the license would go back by pressing the OK button).

Very common situation during the holding of virtual meetings is the need to exchange files, documents, presentations and applications. VCON HD3000 has excellent support system for sharing documents, so users are able to share materials, as they are physically present in the same room.

If it is necessary to send some documents to other participants on remote locations in order to enable them to see that documents on their monitors, it can be done only if all participants have HD3000 system. If the other parties have systems that do not support multicast, then User should switch to unicast, and share the documents with a single location.

\section{The Benefits of the Video Conference in Corporate Environment}

The benefits of using videoconference in corporate environment- in an age of globalization, virtual teams, mobile workers, and distributed campuses - broadly put are the ability to streamline business processes, improve time to market, catalyze creativity, and achieve greater productivity. These benefits play out for organizations by providing:

- Faster and better idea development and faster overall development cycles

- Improved productivity

- Improved project management

- Improved team collaboration, such as brainstorming, developing best of breed ideas out of a group collaboration, and greater ability to reach team consensus

- Faster overall decision making

- Faster deployment of overlapping internal capabilities - the ability to ensure that teams work efficiently instead of duplicating their work

- Workflow integration

- Faster delivery of meeting content

- Shorter/more efficient transcription times

- Travel savings

- Accommodation of environmental considerations

- Entering the digital age (with all of the implied benefits). 
- Improved ability to communicate (Greenberg\&Nilssen, 2008)

By offering the employees more flexibility and greater choice in terms of how and when to communicate and collaborate, companies can become both more efficient. Visual communications presents a 'win-win' opportunity for organizations to meet the challenges of working through the recession, while still showing they recognize the value of their people (Frost\&Sullivan, 2009).

The authors of this paper reached conclusions similar to above mentioned in his earlier research that regarding to the analysis of Serbian market concerning online corporate learning ( Krneta, 2010). Although Serbian companies are facing hard times for running business due to the social and economic crisis:

Frequent virtual meetings with suppliers and clients contributes to strengthening business relations and co-operation, believe $73.3 \%$ of participants in the survey

This doubtless adds up to the quality of service delivery and maintains business costs lower believe $86.7 \%$ of respondents

Some $73.3 \%$ of respondents said that the introduction of videoconferencing contributes greatly to the general image of a company, which further improves its position in the market

The performed research infers that the Serbian market is open to videoconferences, as even $93.3 \%$ of respondents are planning to introduce these systems $(16.6 \%$ of the companies are to implement them into their business in the near future, and $76.7 \%$ in the foreseeable future, as soon as the resources are provided)

\section{Conclusion}

The given work represents a constructive guide for companies introducing corporative trainings and meetings using the video conferencing.

HD 3000 is an example of mid-class compact VC system that can fulfill all of the given requirements for corporative trainings and meetings, which is showed with the comparative analysis of several well known VC systems.

It is mandatory to have the system and the room well prepared, but also it is important to provide the corporative educators and meeting participants with basic knowledge of the videoconferencing scenarios and videoconferencing culture. Because of the previously mentioned preparation importance, two VC corporative scenarios are described and specific practical advices for concrete $\mathrm{VC}$ session preparation are given.

Further work will be focused on detailed analysis and implementation of the given scenarios and subscenarios and improvement of the videoconference techniques in corporate environment. 


\section{References}

Bersin, J. (2007). Top trends in e-learning and corporate training. HR Management Magazine, 5. Retrieved February 2, 2010 from http://www.hrmreport.com/article/Top-trends-in-e-learning-and-corporatetraining/

Boord, M. P. (1997). Video Teletraining: A guide to design, development, and use. USA.

Frost \& Sullivan (2009): Gaining competitive advantages on the road to economic recovery, Business briefing. Retrieved December 2010 from http://www.ivci.com/pdf/whitepaper-using-videoconferencing-for-business-efficiencies-frost.pdf

The Global Development Learning Network. (2005). Retrieved April 2010 from http://www.gdln.org/sectores/gdlntech_sp/D_Files/Videoconferencing\%20Cookbook

Greenberg, A., \& Nilssen, A. (2008). Bringing the meeting room into the digital age. Wainhouse Research, Retrieved November 2010. from http://www.ivci.com/pdf/whitepaper-bringing-the-meeting-roominto-the-digital-age-wainhouse.pdf

Krneta, R., \& Zocevic V. (2010). Analysis of Serbian market concerning online corporate learning, CD Proceedings of Informing Science \& IT Education Conference (InSITE) 2010, pp 407 - 419, Cassino, Italy, June, $19-24,2010$. Retrieved from http://proceedings.informingscience.org/InSITE2010/InSITE10p407-419Krneta816.pdf

Meister, J. (1998). Corporate universities: Lessons in building a world-class work force. McGraw-Hill Professional.

Milošević, M., \& Krneta R. (2008). Infrastructure of the hypermedia lab for master studies in E-learning. Proceedings of Conference Tehnics i Informatics in Education, pp 435 - 443, Čačak, 9-11. May 2008.

Northwest Regional Educational Laboratory. (2000). Planning. Retrieved July, 2010, from http://www.netc.org/digitalbridges/teachersguide/planning.html

Parker, G., \& Hoffman, R. (2006). Meeting excellence: 33 tools to lead meetings that get results. Sebastopol, CA, USA: O’Reilly.

Polycom. (2004). Polycom VSX 8400 datasheet. Retrieved January 2011 from http://www.sohovideo.com/videoconferencing_polycom_vsx_8400_data_sheet.pdf

Prusak, L. (1997). Knowledge in organizations: Resources for the knowledge-based economy. Boston: Butterworth-Heinemann.

Sony. (2008). Sony PCS-XG80 Brochure. Retrieved January 2011 from http://ws.sel.sony.com/PIPWebServices/RetrievePublicAsset/StepID/SEL-asset228263/original/prodbroch_pcsxg55.pdf

Spencer, B. (2006). The purposes of adult education: A short introduction. Toronto, Canada: Thompson Educational Publishing.

Tai, L. (2008). Corporate e-learning: An inside view of IBM's solutions. Oxford Press.

Turek, M. (2009). Five steps for getting the most from your videoconferencing investment. Retrieved December $2010 \mathrm{from} \mathrm{http://www.ivci.com/pdf/whitepaper-getting-the-most-from-your-video-}$ conferencing-investment-frost.pdf

VCON. (2004). VCON HD 3000 datasheet. Retrieved January 2011 from http://www.ivci.com/pdf/vcon_hd3000 data sheet.pdf

VCON. (2010a). Products - Infrastructure - Media Exchange Management - Media Xchange Manager; Benefits. Retrieved December 2010 from http://www.vcon.com/products/management.systems/video.network.management/mxm.benefits.shtml 
VCON. (2010b). Products - Endpoints - Desktop Videoconferencing Systems - vPoint HD - Q\&A. Retrieved December 2010 from http://www.vcon.com/products/endpoints/desktop.video.systems/vPointHD/vPointHD.qa.shtml

\section{Biographies}

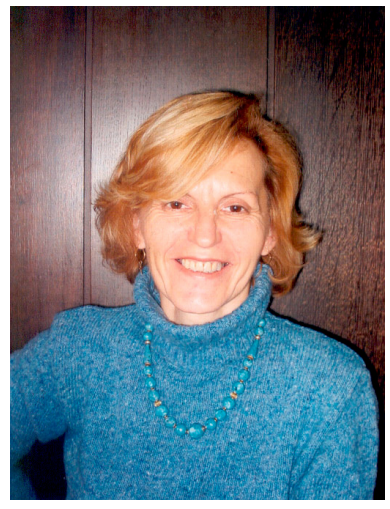

Dr Radojka Krneta is Associate Professor at the Technical Faculty Cacak, University of Kragujevac. She holds B.Sc. in Electronic Engineering at Faculty of Electronic Engineering, University of Nis, M.Sc. in Technical Science at Faculty of Electrical Engineering, University of Belgrade and Ph.D. in Technical Science at Technical Faculty, Cacak, University of Kragujevac in the field of digital signal processing. Her research and pedagogic interests are Computer Technology, Digital Sygnal processing, Digital Control Systems, Energy efficiency and Infrastructure of E-learning Environments. She is autor/co-autor of over 80 research papers, 3 students textbooks and head of several national and international research project. She is head of multimedia laboratory E-lab at Technical Faculty Cacak.

University of Kragujevac, Technical Faculty Cacak, Svetog Save 65, 32000 Cacak, Serbia radojka@ttc.kg.ac.rs, rkrneta@gmail.com www: http://www.tfc.kg.ac.rs/r krneta

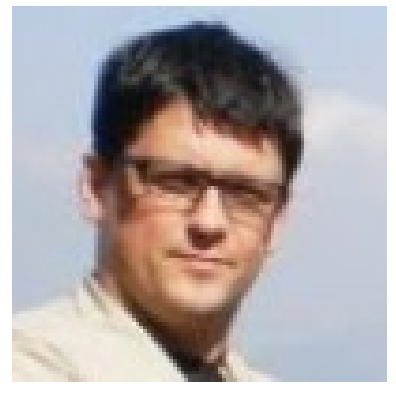

Marjan Milošević, MSc, is a teaching assistant at Technical faculty Čačak, University of Kragujevac. Fields of interest: e-learning, computer networks, network security.

University of Kragujevac, Technical Faculty Cacak, Svetog Save 65, 32000 Cacak, Serbia



Vladimir Zocevic is an employee of Agromehanika service on Cacak. $\mathrm{He}$ holds BSC in Economics, specialised for computer engineering. He is Master of Technical Science, at Technical Faculty, Cacak, University of Kragujevac in the field of information's technology. His researches and professional interests are e - learning, corporate learning, the practical use of videoconferences, the possibility of videoconference application in the corporate purposes, the preparation and organization of virtual meetings. He is author / co - author of few research papers, published in conferences of domestic and international importance.

Agromehanika service, Spomen park bb, 32000 Cacak, Serbia obilics@yahoo.com 